NBER WORKING PAPER SERIES

\title{
CAPITAL CONTROLS, EXCHANGE RATE VOLATILITY AND EXTERNAL VULNERABILITY
}

\author{
Sebastian Edwards \\ Roberto Rigobon \\ Working Paper 11434 \\ http://www.nber.org/papers/w11434
}

\author{
NATIONAL BUREAU OF ECONOMIC RESEARCH \\ 1050 Massachusetts Avenue \\ Cambridge, MA 02138 \\ June 2005
}

We thank Simon Johnson, Aart Kraay and Vincent Reinhart for excellent comments and suggestions on an earlier draft. We also thank the seminar participants at Pompeu Fabra, LACEA 2002 Madrid, ASSA 2004 in San Diego, and the World Bank, for valuable suggestions. Part of this research was done while Roberto Rigobon was visiting the Research Department at the World Bank. He thanks all the members of DEGRG World Bank for their hospitality and comments. All remaining errors are ours. Comments are welcomed and encouraged to sebastian.edwards@anderson.ucla.edu or rigobon@mit.edu. The views expressed herein are those of the author(s) and do not necessarily reflect the views of the National Bureau of Economic Research.

(O2005 by Sebastian Edwards and Roberto Rigobon. All rights reserved. Short sections of text, not to exceed two paragraphs, may be quoted without explicit permission provided that full credit, including $\odot$ notice, is given to the source. 
Capital Controls, Exchange Rate Volatility and External Vulnerability

Sebastian Edwards and Roberto Rigobon

NBER Working Paper No. 11434

June 2005

JEL No. F30, F32

\section{$\underline{\text { ABSTRACT }}$}

We use high frequency data and a new econometric methodology to evaluate the effectiveness of controls on capital inflows. We focus on Chile's experience during the 1990s and investigate whether controls on capital inflows reduced Chile's vulnerability to external shocks. We recognize that changes in the controls will affect the way in which different macro variables relate to each other. We take this problem seriously, and we develop a methodology to deal explicitly with it. The main findings may be summarized as follows: (a) A tightening of capital controls on inflows depreciates the exchange rate. (b) We find that the "vulnerability" of the nominal exchange rate to external factors decreases with a tightening of the capital controls. And (c), we find that a tightening of capital controls increases the unconditional volatility of the exchange rate, but makes this volatility less sensitive to external shocks.

Sebastian Edwards

UCLA Anderson Graduate School of Business

110 Westwood Plaza, Suite C508

Box 951481

Los Angeles, CA 90095-1481

and NBER

sebastian.edwards@anderson.ucla.edu

Roberto Rigobon

Sloan School of Management

MIT, Room E52-431

50 Memorial Drive

Cambridge, MA 02142-1347

and NBER

rigobon@mit.edu 


\title{
CAPITAL CONTROLS, EXCHANGE RATE VOLATILITY, AND EXTERNAL VULNERABILITY
}

By

\author{
SEBASTIAN EDWARDS \\ University of California, Los Angeles \\ and \\ National Bureau of Economic Research \\ and \\ ROBERTO RIGOBON \\ Massachusetts Institute of Technology \\ and \\ National Bureau of Economic Research
}

Revised: June, 2005

\section{Introduction}

Since the currency crises of the 1990s economists have had a renewed interest in understanding the behavior of international capital flows. According to some authors, high capital mobility results in increased macroeconomic instability and, in particular, in more volatile exchange rates and domestic interest rates (Bhagwati 1998, Stiglitz 2002). It has also been argued that in a world of high capital mobility "sudden stops” of capital inflows can be highly disruptive, especially in the emerging countries. According to this view, sudden stops will result in major current account adjustment and in significant declines in economic growth (Dornbusch, Goldfajn and Valdés 1995). Even the International Monetary Fund, a traditional supporter of free capital mobility, has recently supported the gradual opening of the capital account in emerging and transition economies. $^{1}$

A number of economists have argued that restricting short term capital mobility is the best way of dealing with the disruptive effects of sudden shifts in cross boarder capital movements. According to this view, long term capital flows - and in particular FDI - are generally beneficial; short term (and often speculative) flows, on the other 
hand, cause instability and increase vulnerability to financial contagion and crises. ${ }^{2}$

Supporters of restricting short term capital movements have argued that Chile's experience with controls on short term capital inflows during the 1990s was very successful, and that it provides a useful blueprint for other emerging economies. Starting in 1991 all capital flows into Chile -- independently of their maturity or length of stay --, were subject to a one year unremunerated reserve requirement. Thirty percent of the capital flowing into Chile had to be deposited at the Central Bank for one year. ${ }^{3}$ Since no interest was paid on these funds, shorter tem capital faced a higher cost than longer term capital.

The fact that Chile grew very fast during the 1990s - at an average of $7 \%$ percent per year - and that it was not significantly affected by the successive currency crises in the emerging markets, has bolstered the view that emerging economies should restrict short term capital flows. ${ }^{4}$ Indeed, Chile’s controls on capital inflows have been praised from very different quarters. Joseph Stiglitz, a persistent critic of globalization, has been quoted by the New York Times (Sunday February 1, 1998) as saying: "You want to look for policies that discourage hot money but facilitate the flow of long-term loans, and there is evidence that the Chilean approach or some version of it, does this.” And former U.S. Secretary of the Treasury Robert Rubin, an ardent supporter of free capital mobility has said:

1 See Prasad, Rogoff, Wei, and Kose (2003).

2 Recent discussions on the "new" financial architecture have also focused on the merits of controls on capital inflows. Ito (2000) and De Gregorio, Eichengreen, Ito and Wyplosz (2000), for example, have endorsed some variant of Chilean-type controls on inflows. Rogoff (1999) and Kenen (2001), on the other hand, appear to be more skeptical on the benefits of restricting capital inflows. Prasad et al (2003) take a pragmatic approach, and caution that moving towards capital mobility should be done gradually and in the right sequence. Controls on inflows could play a role during this transitional period. See also Rogoff (1999).

$3 \quad$ Initially the rate of the reserve requirement was $10 \%$, and some forms of inflows were excluded. With time, however, the almost all forms of inflows were covered and the rate of the reserve requirements became 30\%. In 1998 the rate was lowered to 0\%. See the discussion in Section II of this paper for details.

4 Macroeconomic stability is only part of the story of Chile's economic success. During the 1970s, 1980s and 1990s Chile relentlessly pursued market-oriented reforms. Although these reforms were initiated under the military dictatorship of General Augusto Pinochet, they were furthered and deepened under three successive democratic administrations. On the early reforms see, for example, Edwards and Edwards (1991); on Chile's long term growth see De Gregorio (2004). 
"[C]ontrol on the inflow, as opposed to the outflow, of short term investments might sometimes make sense as a transitional device. Chile had some apparent success in reducing reliance on volatile funds through restrictions on the inflow of short-term capital...”(Rubin 2003, p. 257).

However, most technical studies on Chile's controls on capital inflows have concluded that this policy was only partially effective. According to Valdés-Prieto and Soto (1998) the controls discouraged short-term flows only after 1995, when their implicit rate of taxation increased significantly. De Gregrio et al (2000) concluded that the decline in short term flows was moderate and was fully compensated by increases in medium term flows. Valdés-Prieto and Soto (1996, p.99) found that "reserve requirements have an insignificant effect on the real exchange rate in the short run," and did not reduce exchange rate volatility. And according to Edwards (1998) and De Gregorio et al (2000) the controls had an insignificant effect on interest rate volatility and levels. ${ }^{5}$ Although these studies have provided some useful insights on the functioning of Chile's controls on capital inflows, they are subject to some important pitfalls. In particular, they have not taken into account the fact that during 1991-1998 - the period when the controls were in effect Chile had an exchange rate band system that limited the extent to which the nominal exchange rate could adjust to shocks. As we show in Section III of this paper, ignoring the nature of Chile's exchange rate regime results in biased estimates when standard econometric techniques are used.

In this paper we use high frequency data and a new econometric methodology to evaluate the functioning of Chilean-type controls on capital inflows. We are particularly interested in understanding whether these controls reduced Chile's vulnerability to external shocks. More specifically, we ask whether the controls on capital inflows reduced the vulnerability of Chile's exchange rate with respect to external shocks in the form of changes in the emerging markets country risk premium (measured by the premium between JP Morgan's EMBI index and the US interest rate). A detailed evaluation of Chile's experience with controls on capital inflows would provide useful

$5 \quad$ See also the studies by Laurens and Cardoso (1998) and Simone and Sorsa (1999). 
information for those seeking to understand how policies restricting capital mobility would affect some key macroeconomic variables. ${ }^{6}$

As pointed out above, however, evaluating the effectiveness of Chilean-style capital controls is not easy. The problem is that traditional empirical strategies - such as regressing macroeconomic variables on an index of capital controls - are subject to the Lucas critique, and will generate biased and inconsistent regression coefficients. Indeed, in order to evaluate properly the effect of capital controls on macroeconomic performance it is necessary to recognize that changes in the controls will affect the way in which different macro variables - the cost of capital and investment, for instance relate to each other. In this paper we take the Lucas critique problem seriously, and we develop a methodology to deal explicitly with it. Specifically, we use the fact that during the period under study the Central Bank of Chile conducted monetary policy within the framework of a target zone exchange rate regime. The presence of this specific monetary policy allows us to disentangle how the controls affected the mapping from "fundamentals" to the exchange rate, and how the vulnerability of the "fundamentals" to external shocks changed with the controls themselves.

The main findings from our analysis may be summarized as follows. First, a tightening in capital controls depreciates the exchange rate. This level effect on the nominal exchange rate should have been expected, given that an increase in the capital controls reduces capital inflows, and causes a deterioration in the balance of payments. ${ }^{7}$ To return to equilibrium, then, an improvement in the current account is required, and hence a real exchange rate depreciation should take place. Surprisingly, most of the papers that have studied the Chilean experience have not found this result; according to most authors the controls had no significant effects on the real exchange rate. ${ }^{8}$ We believe that this is because early studies on the subject ignored the endogenous response

$6 \quad$ Some studies have attempted to analyze empirically the effects of these controls on the Chilean economy. Their focus, however, has not been vulnerability or the international transmission of disturbances. Instead they have analyzed whether the controls allowed the Central Bank to undertake an independent monetary policy, and whether they helped avoid a steep real exchange rate appreciation. See, for example, Valdes-Prieto and Soto (1998), De Gregorio et al (2000), Edwards (1999) and the references cited therein.

7 Most emerging markets that have undertaken modernizing reforms have been subject to massive capital inflows that have generated forces toward currency appreciation. See, for example, Calvo et. al. (1993). 
of the exchange rate to monetary policy. Second, we find that the "vulnerability" of the nominal exchange rate to external factors decreases with a tightening of the capital controls. More specifically, we find that Chile's controls on capital inflows were effective in (partially) isolating the nominal exchange rate from external shocks. Third, we find that a tightening of capital controls increases the unconditional volatility of the exchange rate, but makes this volatility less sensitive to external shocks. The first effect can be explained by the fact that tighter controls are likely to have segmented the Chilean foreign exchange market further, increasing its unconditional volatility. On the other hand, isolating the foreign exchange market means that, in the end, exchange rate volatility is less responsive to external shocks.

Before proceeding it is important to emphasize that our analysis deals only with the macroeconomic vulnerability aspects of exchange rates and capital controls. We do not provide a full cost-benefit analysis of the policy. As argued by Forbes (2003), among others, it is highly likely that this type of controls have important microeconomic costs. A complete policy evaluation of the controls would consider both macro and micro aspects. This task, however, is beyond the scope of this paper.

The rest of the paper is organized as follows: In section 2, we provide a brief description of Chile's experience with controls on capital inflows during the 1990s. In section 3, we develop an empirical model for analyzing the effect of external shocks in a small country that relies on market-based controls on capital inflows. The model is relatively complex, and incorporates the fact that until late 1998 Chile had a managed exchange rate system, based on a wide exchange rate band. Also in this section we present our main econometric results on how Chile's controls affected the way in which external shocks impacted exchange rate volatility. Finally, in Section 4 we present some concluding remarks.

8 See, for example, De Gregorio et. al. (2000). 


\section{Controls on Capital Inflows: Chile's Experience during the 1990s}

Chile introduced market-based controls on capital inflows in June 1991. ${ }^{9}$ Originally all portfolio inflows were subject to a $20 \%$ reserve deposit that earned no interest. If the inflow had a maturity of less than a year, the deposit applied for the duration of the inflow; for longer maturities, the reserve deposit was for one year. In July 1992 the rate of the reserve requirement was raised to 30\%, and its holding period was set at one year, independently of the length of stay of the flow. Also, at that time trade credits and loans related to foreign direct investment became subject to the unremunerated reserve requirement. New changes to this policy were introduced in 1995, when the reserve requirement coverage was extended to include Chilean stocks traded in the New York Stock Exchange (ADRs), “financial” foreign direct investment (FDI), and bond issues. In June of 1998, and as a result of the sudden slowdown of capital inflows associated with the East Asian currency crises, the rate of the reserve requirement was lowered to 10\%, and in September of that year the deposit rate was reduced to zero. Throughout this period Chile also regulated foreign direct investment: until 1992, FDI was subject to a three years minimum stay in the country; at that time the minimum stay was reduced to one year. There were no restrictions on the repatriation of profits from FDI.

In 1991, when capital controls on inflows were introduced, the authorities had four goals in mind: first, to slow down the volume of capital flowing into the country, and to tilt its composition towards longer maturities. Second, to reduce the degree of nominal (and real) exchange rate volatility. Third, to reduce (or at least delay) the real exchange rate appreciation that stemmed from these inflows. And fourth, to allow the Central Bank to implement an independent monetary policy, and to maintain high domestic (real) interest rates (De Gregorio et al 2000, Massad 1998).

Chile's system of unremunerated reserve requirements was equivalent to a tax on capital inflows. What made this policy particularly interesting was that the rate of the tax is not constant; in fact, it varied constantly. This was because the rate of the tax depended both on the period of time during which the funds stayed in the country, as well

$9 \quad$ Chile also implemented controls on inflows during the 1980s. That episode was clearly unsuccessful. For details see Edwards and Edwards (1991) and Edwards (1998a, b). 
as on the opportunity cost of these funds (i.e. "the" world rate of interest). As shown by Valdés-Prieto and Soto (1998) and De Gregorio, Edwards and Valdes (2000), the tax equivalent for funds that stayed in the country for $k$ months, is given by the following expression:

$$
\tau(k)=\frac{r^{*} \lambda}{1-\lambda} \frac{\rho}{k}
$$

where $r^{*}$ is an international interest rate that captures the opportunity cost of the reserve requirement, $\lambda$ is the proportion of the funds that has to be deposited at the Central Bank, and $\rho$ is the period of time (measured in months) that the deposit has to be kept in the Central Bank.

Figure 1 contains estimates of this tax-equivalent for three values of $k$ : six months, one year and three years. Three aspects of this figure are particularly interesting: first, the rate of the tax is inversely related to the length of stay of the funds in the country. This, of course, was exactly the intent of the policy, as the authorities wanted to discourage short-term inflows. Second, the rate of the tax is quite high even for a three year period. During 1997, for example, the average tax for 3 year-funds was 80 basis points. And third, the tax equivalent varied through time, both because the rate of the required deposit was altered and because the opportunity cost of the unremunerated deposits changed.

Between 1988 and 1998 shorter-term flows into Chile - that is, flows with less than a one year maturity-- declined steeply relative to longer term capital. The percentage of the county's liabilities in hands of foreigners maturing within a year also declined in the period following the imposition of controls (De Gregorio et al 2000). By late 1996 Chile had a lower percentage of short-term debt to G-10 banks than any of the East Asian countries, with the exception of Malaysia (Edwards 1998b).

A traditional shortcoming of capital controls (either on outflows or inflows) is that it is relatively easy for investors to avoid them. Valdés-Prieto and Soto (1998), for example, have argued that in spite of the authorities' efforts to close loopholes, Chile's controls were subject to considerable evasion. Cowan and De Gregorio (1998) 
acknowledged this fact, and constructed an index of the "power" of the controls. This index takes a value of one if there is no (or very little) evasion, and takes a value of zero

if there is complete evasion. According to them this index reached its lowest value during the second quarter of 1995; by late 1997 and early 1998 this index had reached a value of 0.8 .

Some authors have used regression analysis to investigate the determinants of capital flows in Chile. Soto (1997) and De Gregorio et al (2000), for example, estimated a system of VARs using monthly data to analyze the way in which capital controls have affected the volume and composition of capital inflows. Their results suggest that the tax on capital movements discouraged short-term inflows. These analyses indicate, however, that the reduction in shorter-term flows was fully compensated by increases in longerterm capital inflows and that, consequently, aggregate capital moving into Chile was not altered by this policy. Moreover, Valdés-Prieto and Soto (1998) have argued that the controls only became effective in discouraging short-term flows after 1995, when its actual rate increased significantly. ${ }^{10}$

\section{Measuring the Effectiveness of Capital Controls}

A serious difficulty in evaluating whether Chile's capital controls policy was successful in reducing macroeconomic volatility - and in particular, in reducing exchange rate volatility -- is that it was implemented at the same time as the country had a (credible) target-zone exchange rate regime. The co-existence of these two policies controls on inflows and a target zone - make it difficult to determine if reduced exchange rate volatility is the result of the controls, or of the fact that the observed exchange rate is close to one of the bands. This implies a problem of identification from the monetary policy choice to the observed exchange rate. However, there also exists a channel from capital controls to the way a target zone works. As it is well known, a credible target zone regime implies a mapping from a fundamental exchange rate to an observed exchange rate that depends on the stochastic process of such fundamentals. Therefore, if the capital controls are effective in reducing exchange rate volatility, when the controls are tightened the volatility of the fundamental driving the exchange rate decreases, altering the 
mapping from the same fundamentals to the observed exchange rate. This phenomenon is highly related to the Lucas critique: capital controls and the management of the exchange rate are intertwined - a change in one modifies the effectiveness of the other, and viceversa.

In this paper we develop a methodology to disentangle these effects. We take seriously the bands' exchange rate regime announced by the Chilean Central Bank, and we estimate the implied "fundamentals" determining the observed exchange rate - this is equivalent to estimating a shadow exchange rate that would have prevailed in the absence of the intervention implied by the target-zone exchange rate regime. Once the shadow exchange rate has been computed in the first stage of the analysis, we can then evaluate the effectiveness of the capital controls by measuring the pass through from external shocks to the shadow exchange rate, under alternative intensities of capital controls. We carry out this second stage by estimating a series of GARCH regressions on the conditional variance of the shadow exchange rate.

\subsection{Data}

The data are taken from Datastream and the Central Bank of Chile. Exchange rate data correspond to the daily exchange rate, the central parity and the target-zone bands. We also use daily data on domestic peso denominated interest rates on 30-day deposits, and on the equivalent tax rate implied by the controls - computed according to equation (1). Finally, we used two alternative sources of external shocks - changes in U.S. interest rates (30-day deposit rates), and the JP Morgan EMBI+ index that excludes Chile. The sample corresponds to the period in which the target zone regime was in place - starting in January 1991 until September $2^{\text {nd }}$, 1999. (Daily domestic interest rates were only available from January $\left.1^{\text {st }} 1994.\right)$

\subsection{Estimation}

To estimate the shadow exchange rate - or exchange rate that would have prevailed in the absence of intervention -- we assume that the announcement of the target zone regime is credible. Conditional on taking this announcement seriously, the mapping 
from the shadow exchange rate to the observed nominal exchange rate is uniquely determined by the bands and by the stochastic properties of the exchange rate process.

We assume that the mean of the shadow exchange rate is constant across time; the variance, on the other hand, is assumed to be time dependent. ${ }^{11}$ This means that at each instant in time, the mapping from the shadow to the observed exchange rate will shift. This assumption is required because our purpose is to evaluate how the capital controls have changed the stochastic properties of the fundamentals determining the exchange rate. Therefore, given that the tightness of the capital controls changes through time -recall equation (1) --, and that the shocks are characterized by conditional heteroskedasticity, we should also expect the shadow exchange rate to have conditional heteroskedasticity as well.

To derive the observed exchange rate as a function of the shadow exchange rate we follow Bertola and Caballero (1992) closely. Assume that money demand in each country is given by:

$$
\begin{aligned}
& m_{t}^{*}-p_{t}^{*}=-\alpha i_{t}^{*} \\
& m_{t}-p_{t}=-\alpha i_{t}
\end{aligned}
$$

Assume further that both purchasing power parity (PPP) and uncovered interest parity (UIP) hold. This implies that the exchange rate is:

$$
e_{t}=m_{t}-m_{t}^{*}+\alpha \frac{E\left[d e_{t}\right]}{d t}
$$

where we have substituted the money demands in the PPP equation and use the fact that the interest rate differential is equal to the expected exchange rate depreciation. In this simple equation the changes in money supplies are the "fundamentals" or shadow

11 We can allow the mean to change and makes no difference in the estimation. Means, however, are very badly estimated when the process follows a random walk. We faced the exact same estimation issues in our procedure. Nevertheless, we were encouraged by the fact that allowing the trend to vary or to force it to be the same produced (qualitatively) very similar results. 
exchange rate that govern the exchange rate dynamics. We assume that the fundamentals are given by:

$$
f_{t}=\mu_{t} d t+\sigma_{t} d z_{t}
$$

where the mean and the variance are measurable but time shifting. Using Ito's lemma it is easy to show that the exchange rate satisfies the following differential equation:

$$
e_{t}=f_{t}+\alpha\left[\mu_{t} \frac{\partial e_{t}}{\partial f_{t}}+\frac{1}{2} \sigma_{t} \frac{\partial^{2} e_{t}}{\partial f_{t}^{2}}\right]
$$

The solution to the differential equation is:

$$
e_{t}\left(f_{t}\right)=\alpha \mu_{t}+f_{t}+A_{t} \exp \left(\lambda_{1 t} f_{t}\right)+B_{t} \exp \left(\lambda_{2 t} f_{t}\right),
$$

where $\lambda_{1 t}$ and $\lambda_{2 t}$ satisfy

$$
\lambda_{t}=-\frac{\mu_{t}}{\sigma_{t}} \pm \sqrt{\left(\frac{\mu_{t}}{\sigma_{t}}\right)^{2}+\frac{2}{\alpha \sigma_{t}}}
$$

To pin-down the coefficients in the homogeneous solution to the differential equation we require boundary conditions. These are specified by the bands of the target zone and the credibility of the exchange rate regime.

The exchange rate bands in Chile moved frequently - see Figure 2. However, a sizeable proportion of this movement is predictable in the sense that it depended on how the central parity is computed. Throughout the period under consideration the Central Bank set the central parity as some weighted average of past realizations - which means that the bands can be computed according to the information available at time $t^{12}$ Indeed, during our sample there are only 5 band alignments (See Figure 2): 
- On January $2^{\text {nd }} 1991$ the band is set to 5 percent of the central parity;

- On January $23^{\text {rd }} 1992$ the band is expanded to 10 percent;

- On January $21^{\text {st }} 1997$ the band is further expanded to 12.5 percent of the central parity;

- On June $26^{\text {th }} 1998$ the band is heavily tightened to an upper band of only 2 percent and a lower band of 3.5 percent;

- On September $17^{\text {th }} 1998$ both bands are set to 3.51 percent, and the bands are progressively increased every day until they become almost 12 percent in September $2^{\text {nd }} 1999$ when the regime was abandoned.

We assume that the probability that the bands are realigned increases when the exchange rate is close to the band. More specifically, this probability is computed as the number of realignments that occurred divided by the number of observations in which the exchange rate was closer than 0.5 percent of the band.

At each point in time we have the following boundary conditions:

$$
\begin{aligned}
& f_{t} \in\left[\underline{f_{t}}, \overline{f_{t}}\right] \\
& \underline{e_{t}}=\alpha \mu_{t}+\underline{f_{t}}+A_{t} \exp \left(\lambda_{1 t} \underline{f_{t}}\right)+B_{t} \exp \left(\lambda_{2 t} \underline{f_{t}}\right) \\
& \overline{\overline{e_{t}}}=\alpha \mu_{t}+\overline{\overline{f_{t}}}+A_{t} \exp \left(\lambda_{1 t} \overline{f_{t}}\right)+B_{t} \exp \left(\lambda_{2 t} \overline{f_{t}}\right),
\end{aligned}
$$

where $\underline{f}$ and $\bar{f}_{t}$ represent the lower and upper implied shadow exchange rate bands. These boundary conditions are known as the value matching conditions. The smooth pasting conditions take into account the fact that the bands are time varying and incorporate the probability of realignment, as well as the predicted changes in the central parity. As may be seen in Figure 2, most of the changes in the central parity and the width of the band are relatively small and follow the predictable process described above. We compute the expected change in each of the bands, and write the smooth pasting conditions as follows: 


$$
\begin{aligned}
& \underline{\hat{e}_{t}}=1+A_{t} \lambda_{1 t} \exp \left(\lambda_{1 t} \underline{f_{t}}\right)+B_{t} \lambda_{2 t} \exp \left(\lambda_{2 t} \underline{f_{t}}\right) \\
& \overline{\hat{e}_{t}}=1+A_{t} \lambda_{1 t} \exp \left(\lambda_{1 t} \overline{\bar{f}}\right)+B_{t} \lambda_{2 t} \exp \left(\lambda_{2 t} \overline{\bar{f}}\right)
\end{aligned}
$$

Our data set includes the following information: the actual (observed) exchange

rate $\left(e_{t}\right)$, the bands $\left(\underline{e_{t}}\right.$ and $\left.\overline{e_{t}}\right)$, and the probability of realignment (reflected in the fact that the smooth pasting conditions are not equated to zero). We also have knowledge on the backward looking rule used by the central bank to determine the central parity.

Our objective is to estimate the shadow exchange rate $\left(f_{t}\right)$, the bands $\left[\underline{f}_{t}, \bar{f}_{t}\right]$, the coefficients $A_{t}$ and $B_{t}$, and the time varying moments describing the fundamentals' process: $\mu_{t}$ and $\sigma_{t}$. Notice that this is a highly complex non-linear problem: we have as many stochastic differential equations as observations. The mapping from the fundamental or the shadow exchange rate to the observed exchange rate changes with the conditional mean and variance. If capital controls are effective and change the volatility of the fundamental, or the pass through from external shocks to the fundamentals, then the mapping between the shadow and the observed will change as well. We take into account these changes in our estimation, and therefore, at least in a small dimension we are dealing with a basic form of the Lucas critique. ${ }^{13}$

\subsection{Estimating the shadow exchange rate}

We assume that the variance of the shadow exchange rate moves smoothly - and that it can be approximated by a moving average. Under this assumption, the conditional variance at some time $t$ is given by the variance of the previous $n$ observations. This method allows us a very flexible specification where we do not have to commit to a particular parametrization of the variance process. We did some sensitivity analysis on these assumptions that is discussed below.

The procedure of estimation is by iteration, and involves the following steps:

13 Obviously it could be argued that we only deal with a small dimension of the Lucas critique which is true. For example, the validity or changes in the alignments of the bands are assumed exogenous and independent of the capital controls. 
a) Initialize the shadow exchange rate equal to the observed exchange rate: $f_{t}^{0}=e_{t}$. This is the first iteration.

b) Compute the mean return in the fundamentals (we are assuming that the mean return is constant $\mu_{t}=\mu$ ) and the rolling variance of the fundamentals $\left(\sigma_{t}=\operatorname{var}\left(f_{t-n}^{i}: f_{t-1}^{i}\right)\right)$. For some $n$ that represents a reasonable window (we used 5, 10, 20 and 60 days and the results are very similar. All the results we show are those from the 5 days)

c) Using the mean return and the rolling variance, compute the series of $\lambda_{1 t}$ and $\lambda_{2 t}$ that prevails at each time $t$.

d) Using the observed bands $\left[\underline{e_{t}}, \overline{e_{t}}\right]$, the $\lambda_{1 t}$ and $\lambda_{2 t}$ previously computed, and the expected changes in the bands $\left[\underline{\hat{e}_{t}}, \overline{\hat{e}}_{t}\right]$ we compute $\left(A_{t}, B_{t}, \underline{f_{t}}, \bar{f}_{t}\right)$ using equations (7) and (8). Note that at each time $t$, equations (7) and (8) form a system of four equations in four unknowns - hence, for each observation we solve the system of equations.

e) Finally, using equation (6) we solve for the implied fundamental that explains the exchange rate. This provides an estimate of the shadow exchange rate: $f_{t}^{i+1}$.

f) Jump to step (b) and continue iterating until convergence has been achieved in the shadow exchange rate.

Because the mapping is unique, continuous and differentiable between $\underline{f_{t}}, \overline{f_{t}}$ the iteration has a fixed point. In the end, we estimate the shadow exchange rate, the implied shadow exchange rate's bands, and the conditional variance of the shadow exchange rate that is consistent with the observed exchange rate and the announced bands.

Notice that in developing this procedure we have made two important assumptions: first, we have assumed that the mean returns are constant. This is mainly for convenience. It is well known that mean returns are poorly estimated when the time horizon is short. In our case, however, the (daily) data runs from the beginning of the 90 's to the end of the 90 's. If we were to estimate a yearly mean return we would 
introduce a noisy estimate in the procedure. However, when we allowed the trend to change, the shadow exchange rate was almost identical to the one we estimated forcing the trend to be constant. Thus, we view this restriction as innocuous. Second, we have assumed that the central bank only intervenes when the exchange rate is close to the band, following precisely what a target zone exchange rate regime implies. We made this assumption because there are no data on daily interventions for the period under study. ${ }^{14}$ We were only able to compile monthly interventions; when we re-estimate the estimate at this lower frequency, the results are quite similar to those obtained under our assumption that intervention only takes in the neighborhood of the bands, but the standard errors computed in the next section became large.

The results from the estimation of the shadow exchange rate are shown in Figure 3 , where in order to avoid clutter we have not shown the central parity. As may be seen, the shadow exchange rate and the actual one are fairly close. The bands and the fundamental are measured on the left-hand side scale, and the dotted line indicates the difference between the shadow exchange rate and the observed exchange rate, which is measured in the right vertical axis. From the theory we know that when the exchange rate is below the central parity the observed exchange rate is larger than the shadow exchange rate. The opposite occurs when the exchange rate is above the central parity. ${ }^{15}$ Notice that indeed this is the relationship between the exchange rate and the shadow exchange rate. At the beginning of the sample the exchange rate is usually below the parity and the difference to the shadow one are always negative. The opposite takes place when the exchange rate is positive. Furthermore, the theory also implies that the closer the exchange rate is to the band the larger the deviations should be (ceteris paribus). Our shadow exchange rate follows exactly such prescription.

Finally, we know that when the shadow exchange rate is less volatile, the mapping becomes steeper and the differences between the observed exchange rate and the shadow exchange rate are smaller. This is also the case in our estimations. In Figure 4, we show the bands and shadow exchange rate without the central parity; we also show

\footnotetext{
14 We thank Rodrigo Valdes from the Central Bank of Chile for confirming this to us.

15 This is a standard result in the target zone literature. In our setup, the slope of the mapping at the central parity is one and it goes to zero when the exchange rate approaches the bands.
} 
the shadow exchange rate conditional (rolling) volatility. As may be seen, there are important spikes in the second moments. These coincide either with realignments in Chile's exchange rate bands, or with major international crises, such as the East Asian crisis of 1997 and the Russian crisis of 1998. Observe that the times during which the shadow exchange is more volatile are those in which the difference between the shadow and the nominal exchange rate become larger, in absolute value.

\subsection{External vulnerability and Capital controls}

After the shadow exchange rate has been computed, the second step is to estimate a GARCH model to evaluate the importance (and role) of capital controls in the propagation of external shocks.

We assume that changes in the extent of the controls are exogenous to the exchange rate. This is a reasonable assumption, since changes in the tax equivalence of capital controls tax rate are not associated with realignments in the band - See Figure 5. Indeed, these two variables are only related when the controls are abandoned in 1998 and the band is widened. Furthermore, changes in the tax equivalence of the controls are largely the result changes in international interest rates - recall equation (1).

The equivalent tax rate is computed using equation (1), and the GARCH specification is the following:

$$
\begin{aligned}
& f_{t}=c_{0}+\beta_{0} x_{t}+\beta_{1} \tau_{t}+\beta_{2} x_{t} \cdot \tau_{t}+\varepsilon_{t} \\
& \varepsilon_{t} \sim N\left(0, h_{t}\right) \\
& h_{t}=\eta_{0}+\eta_{1} h_{t-1}+\eta_{2} \varepsilon_{t-1}^{2}+\eta_{3} x_{t}+\eta_{4} \tau_{t}+\eta_{5} x_{t} \cdot \tau_{t}
\end{aligned}
$$

where $f_{t}$ is the shadow exchange rate computed in the first step, $x_{t}$ is the external shock, $\tau_{t}$ is the equivalent tax rate on capital inflows, $x_{t} \cdot \tau_{t}$ is a term that interacts the external shock and the tax equivalent of the capital controls, and $\varepsilon_{t}$ is the heteroskedastic residual. All variables have been de-meaned and normalized by their standard deviations. ${ }^{16}$ We 
introduced other controls in the regression, such as US interest rates. The exogenous shock $x_{t}$ is given by (changes in) the JP Morgan's EMBI+ spread for Latin America, excluding Chile. Our main interest is to understand how the external shock affects the shadow exchange rate and its conditional variance, for different levels of the tax equivalence of the capital controls. We estimate the model with no lags, with one lag, and with two lags.

\subsubsection{The Mean Equation}

The model is estimated by maximum likelihood, and the results for the mean equation are in Table 1; the conditional variance equation estimates are in Table 2. The coefficients indicated as $x_{t}, \tau_{t}, x_{t} \tau_{t}$ refer to the contemporaneous effects of the external shock, the capital control tax, and the interaction term. We discuss first the results for the mean equation in Table 1. As may be seen in the first regression, an increase in the emerging market's country risk spread $x_{t}$ depreciates the shadow exchange rate. Similarly, an increase in the extent of capital controls $\tau_{t}$ depreciates the exchange rate. Both effects are statistically significant and have the expected sign. This is because both

of these developments - higher EMBI+ country risk spread and higher tax equivalence of the controls - make domestic securities less attractive, and result in a decline in the volume of capital flowing into the country. Hence, to return to equilibrium an improvement in the current account is needed - which requires a depreciation of the exchange rate.

The results in Table 1 also show that the interaction term $x_{t} \tau_{t}$ is negative, and statistically significant, for all the cases analyzed. This indicates that an increase in the extent of capital controls makes the level of the shadow exchange rate less sensible to external shocks. That is, according to these results, Chile's controls on inflows were able to (partially) isolate the country - or at least its exchange rate - from external disturbances.

In order to illustrate the meaning of these results, it is interesting to analyze the impulse response of the exchange rate to an external shock under different levels of capital control. In practice, the external shocks are very persistent, so we shocked the 
model by an innovation with a high degree of persistence (the AR coefficient is almost 0.8). The shock is equal to four standard deviations of the EMBI+ spread. ${ }^{17}$ Three simulations are depicted: one in which the capital controls are zero, denoted by e_0. One in which the capital controls are 0.5 (e_1); and one in which they are equal to 1 (e_2). Remember that we normalized the indexes by their standard deviation hence this implies a capital control equal to half and one standard deviations, respectively. In our sample, the average effective six months tax (computed in equation 1) is 3.16, with a maximum of 4.69 and a standard deviation of 1.29.

The results are in Figure 6. Three features of this Figure are worth discussing. The first one has to do with the level effect: a higher capital control tax implies a more depreciated exchange rate (in this diagram up means depreciation). This result is consistent with what we should expect if the capital controls were effective. As was mentioned before, starting from balance of payments equilibrium and increase in the capital controls reduces capital inflows, and generates an incipient balance of payments deficit that has to be compensated by a surplus in the current account. This surplus, in turn, is achieved through a real depreciation.

Second, according to Figure 6 an external shock to the emerging markets' interest rate depreciates the exchange rate. However, for tighter controls, the less sensitive the exchange rate is to the external shock - that is, the degree of vulnerability is smaller.

Third, the persistence of the shocks differs with the degree of capital controls: tighter controls imply more persistent deviations. Again, if the controls are effective, deviations from equilibrium are harder to arbitrage out. Capital controls segment the markets and the fact that smaller deviations are more persistent should not be surprising. Although this result is in line with the theory, it is only found when the endogenous response of the monetary policy to the capital controls is taken into account.

\subsubsection{The Variance Equation}

Having devoted the previous discussion to the mean equation, we now turn our attention to the variance equation, which we present in Table 2. Note, first, that an increase in the EMBI+ spread increases the variance of the shadow exchange rate. This

17 We choose four standard deviations to highlight the movement of big external disturbances. 
coefficient has the expected sign and it is statistically significant in all the specifications. We interpret the increase in the emerging markets' spread as a "bad” shock to Chile; and therefore, we expect an increase in the variance and a depreciation of the exchange rate. This is, indeed, what we report in tables 1 and s. Second, an increase in the tax equivalence results in a higher conditional variance of the shadow exchange rate. That is, tighter controls tend to increase the unconditional volatility of the shadow exchange rate. And third, the interactive term for the external shock and the tax equivalent is negative, and significantly so for the model with one lag. These results are not as sharp as those for the mean equation, and suggest that capital controls either do not affect the way in which foreign shocks impact exchange rate volatility, or have a weak “isolation” effect.

As in the case of the mean equation, the main results are nicely captured by an impulse response function - see Figure 7. As before, there is a level effect of increasing the capital controls. The shadow exchange rate becomes more volatile when the capital controls are imposed - but the benefit is that external shocks have a smaller overall effect on the variance.

The increase in the exchange rate unconditional volatility could be rationalized as the result of the market becoming more segmented when the capital controls are increased. It is important to highlight that we did not find this effect when the same regression was run directly on the observed - as opposed to the shadow -- exchange rate. The reason for this is simple. Given that through most of the period under study the exchange rate in Chile was close to the lower band, all volatilities are collapsed toward zero - meaning that external shocks have small or negligible impact on the second moments. Computing the shadow exchange rate, as we did in the first step, makes very clear what is the trade off faced by the monetary authority.

An interesting result from our estimation is the relationship between the predicted variance of the shadow exchange rate and the tax rate. Both of these series are plotted in Figure 8. The tax rate is measured on the right hand axis and the variance is measured on the left-hand side. Note that in the earlier periods in the sample - that is before 1996 increases in the equivalent tax rate were associated with significant reductions in the conditional volatility. Later in the sample, changes in the tax rate seem to have no effect on the variance of the shadow exchange rate. This indicates that capital controls ceased to 
be effective after mid-1997, a period when capital flows to all emerging markets plunged severely. Not surprisingly, then, in the absence of capital inflows, market-based capital controls on the inflows, by construction, should be ineffective. Our evidence suggests that indeed the changes in the policy were unable to affect the stability of the exchange rate in the later part of the sample; they were effective, however, during the earlier period.

\subsection{Robustness and sensitivity analysis}

To determine how robust our findings are to changes in the specification we performed several sensitivity analyses. Here we present the main results. ${ }^{18}$ Our estimation procedure has two steps. In the first step we compute the shadow exchange rate that would have prevailed in the absence of a target zone regime, and in the second step we analyze the effect that external shocks and the implied tax of capital controls have on the level and volatility of the shadow exchange rate. We perform sensitivity analyses to both of them.

First, we checked the estimation of the shadow exchange rate by changing the rolling window to compute the variance. The results presented above are for a 5-day window; in the robustness analysis we tested 10, 20 and 60-day windows. The results are qualitatively the same. The only difference is the magnitude of the coefficients in the second step (GARCH) but not their significance, nor their signs. In general, the longer the window is, the larger the coefficients in the regression. We also allowed the trend to shift through time, and the two shadow exchange rates were almost identical. Additionally, we estimated the model assuming that no realignment was possible, i.e. that the bands were fully credible. The shadow exchange rate computed was almost identical to the one in our preferred specification.

Second, we evaluated the sensitivity of the results in the GARCH specification. The first sensitivity analysis we run changed the number of lags in the mean and variance equations. We estimated the model using 0, 1, and 2 lags (all the results shown in the respective tables), and even though the impulse responses vary, the main message is the same as the one discussed in the preceding section. We also included the domestic 
interest rates in the estimation of the GARCH. In this case, unfortunately, a sizeable part of the sample has to be dropped and several of the significant coefficients were not significant in this exercise. Nevertheless, the point estimates were similar to Tables 1 and 2, suggesting that this is a problem of small samples and not of robustness. Finally, we run the GARCH in first differences, and introducing other controls such as the U.S. stock market. Also, instead of estimating a GARCH model we allow for other types of volatility models. For example, we took directly the estimated variance from the first step and regressed that on the controls taking into account that the residuals have an MA structure (to correct for the serial correlation). The point estimates changed, but the message was unaffected in this specification as well

An important caveat is that the model assumes that interventions only occurred close to the bands. This was not always the case for Chile. Unfortunately, and as pointed out earlier, we did not have information about daily interventions. For the period under consideration we were only able to collect bi-weekly intervention data. One possibility we tried was to estimate the model using bi-weekly data. However, the amount of information dropped is tremendous and in the end most estimates were not statistically different from zero (except for the level effects in the mean and the variance equation). As a comparison, we estimated the biweekly model without interventions - which is the same model that we estimated here but at a lower frequency - and the model with interventions. We compared the two shadow exchange rates from these two exercises and they were almost identical, suggesting that the effect of the intervention is either small, or it disappears after a few days. Indeed, we were not particularly surprised by this result. Recent research in the effectiveness of central bank intervention in exchange rates has shown that most of the impact of the intervention takes place within a day or two. ${ }^{19}$ And certainly it disappears after 10 days.

Three additional issues are worth mentioning. First, we have obviated the issue of evasion and assumed that capital controls were fully effective. There is evidence that this was not the case in Chile. However, taking them into account should make our results 
stronger - not weaker. ${ }^{20}$ Second, we have assumed that other policies are not endogenous to capital controls - such as fiscal policy and foreign borrowing. Future research should incorporate these issues in order to understand fully the consequences of capital controls on macroeconomic vulnerability. Third, and possibly the most important, we have taken the central bank announcements with respect to the exchange rate system to be fully credible. We have assumed that the managed exchange rate announcement is indeed implemented, and that it is believed by the market, even though in our sample the central bank realigned the bands five times. As in the case of evasion, if the monetary policy is not credible the distance between the shadow and the actual exchange rate should be smaller. In fact, a non-credible target zone implies that the shadow and the observed exchange rates are identical. Therefore, not including the lack of credibility of the managed exchange rate should reduce our coefficients. Nevertheless, if the capital controls have an impact on the degree of credibility of the exchange rate regime, then our results will be affected. Unfortunately we do not have information to deal with this issue. Finally, we estimated the model using a two-step procedure. We do this for simplicity. A more efficient method would be to incorporate the GARCH model into the estimation of the shadow exchange rate and estimate the complete model simultaneously. This is a highly intractable procedure, and unlikely to change the results shown here. Certainly, even with our two-steps procedure we obtain significant effects.

\section{Conclusions and Policy implications}

In practice, most countries that have capital controls manage their exchange rates. Under these circumstances evaluating the effectiveness of the controls by looking at the co-movement between the observed exchange rate and the shocks is likely to capture the combination of both the controls and the active monetary and exchange rate policies. Without a clear model of how monetary policy is conducted, this exercise cannot be solved, and it is likely to produce biased results and misleading policy analyses. Furthermore, it is not enough just to specify a parsimonious monetary policy reaction

20 In other words, the evasion implies that the effect of the capital controls on the exchange rate are smaller in practice than the theoretical ones. Hence, our estimates should reflect the coefficients assuming evasion which means that all the true effects are larger than the ones shown here. 
function, because one of the purposes of capital controls is to change the stochastic properties of the fundamentals driving the exchange rate (mean, variances, vulnerabilities, and so on) - what we have denoted in this paper as the shadow exchange rate. Therefore, the monetary reaction function is also likely to change when controls are imposed, or when the extent of controls changes.

In this paper we have attempted to disentangle the role played by capital controls from the management of the exchange rate. In doing so, we specify how monetary policy is conducted - which in the case of Chile between 1991 and 1999 is described by the target zone literature. The target zone literature produces monetary policy reaction functions that depend on the fundamentals, as well as, on their stochastic properties. Therefore, by using this tool we are able to incorporate the Lucas critique - at least in some form - on how changes in the stochastic process of the driving forces of the exchange rate influence the monetary policy reaction function and the observed exchange rate.

The contributions of this paper are twofold. First, to estimate a shadow exchange rate that "cleans" the observed exchange rate by the endogenous monetary policy reaction function. This procedure takes into account that the mapping between the two changes through time, and is an explicit function of the stochastic properties of the fundamentals. Second, using the shadow exchange rate estimated in step one we are able to evaluate how the capital controls have affected the exchange rate. We find that a tightening of the capital controls is associated with:

- a depreciation of the nominal exchange rate;

- an increase in the unconditional variance of the nominal exchange rate;

- and with a reduction in the vulnerability of the nominal exchange rate to external shocks, both to the mean and to the variance.

Our results are important because using standard techniques - that is techniques that do not correct for the endogenous reaction of monetary policy - it is not possible to evaluate properly if controls have been effective. Our results indicate that capital controls on inflows have been - at least in Chile - more effective than what previous studies had 
suggested, in the sense of helping reduce the impact of external shocks on the nominal exchange rate. That is, our results indicate that Chile's controls on inflows helped reduce the country's vulnerability to external disturbances. It is important to emphasize, however, that we have made no attempt to provide a full cost-benefit analysis of the capital controls. By restricting international exchange of contingent claims, capital controls have microeconomic costs. A complete policy evaluation of the controls would consider both the macroeconomic and microeconomic aspects of the policy. This task, however, is beyond the scope of this paper. 


\section{References:}

Bhagwati, J. (1998): “The Capital Myth. The Difference between Trade in Widgets and Dollars”. Economic Affairs, 77(3): 7-12.

Bertola G. and R. Caballero (1992): "Target Zones and Realignments," The American Economic Review, 82 (5): 520-536.

Calvo, G., Leiderman, L. and C. Reinhart (1993): “Capital Inflows and Real Exchange Rate Appreciation in Latin America: The Role of External Factors,” IMF Staff Papers, 40(1): 108-151.

Cardoso, J. and B. Laurens. (1998). “Managing Capital Flows: The Experience of Chile” IMF Working Paper 98/18.

Cowan, K. and J. De Gregorio. (1998). “Exchange Rate Policies and Capital Account Management.” In R. Glick ed. Managing Capital Flows and Exchange Rates, Cambridge: Cambridge University Press, 465-488.

De Gregorio, J. (2001). “La Política Cambiaria.” Economic Policy Paper No. 2. Central Bank of Chile.

De Gregorio, J., Eichengreen, B. J., Ito, T. and C. Wyplosz (1999): Independent and Accountable IMF, Center for Economic and Policy Research.

De Gregorio, J., Edwards, S. and R. Valdes (2000): “Controls on Capital Inflows: Do they Work?”, Journal of Development Economics, Vol. 63, pp. 59-83.

De Gregorio, J. (2004). “Economic Growth in Chile: Evidence, Sources and Prospects.” Working Paper No. 298. Central Bank of Chile. 
Dominguez, K.M. and J. A. Frankel. (1993): “Foreign Exchange Intervention: An Empirical Assessment”. In J. A. Frankel, editor, On Exchange Rates, pages 327345. MIT Press.

Eichengreen, B. J. (1999): “Toward a New International Financial Architecture”. Institute for International Economics. Washington D.C.

Edwards, S. (1998a): “Capital Inflows into Latin America: A Stop-Go Story?” NBER Working Paper. No. 6441.

(1998b): “Capital Flows, Real Exchange Rates, and Capital Controls: Some Latin American Experiences.” NBER Working Paper. No. 6800.

(1999): “How Effective are Capital Controls”. Journal of Economic Perspectives. 13 (4): 65-84.

Edwards, S. and A. Edwards (1991): Monetarism and Liberalization: The Chilean Experiment. Chicago, University of Chicago Press, second edition.

Forbes, K. J. (2003): “One Cost of the Chilean Capital Controls: Increased Financial Constraints for Smallest Traded Firms.” NBER Working Paper 9777.

Ito, T. (2002): "Is Foreign Exchange Intervention Effective? The Japanese Experiences in the 1990s.” NBER Working Paper 8914.

Kearns, J. and R. Rigobon (2003): “Identifying the Effectiveness of Central Bank Interventions: Evidence from Australia and Japan”, Journal of International Economics. 
Kenen, P. (2001): The International Financial Architecture: What's New? What's Missing?, Institute for International Economics, Washington.

Krugman, P (1999): “Currency Crises,” in M. Feldstein (Ed.). International Capital Flows. NBER and Chicago University Press, Ch. 8, 421-440.

Massad, C. (1998): “La Política Monetaria en Chile”. Revista de Economía Chilena. 1 (1). Central Bank of Chile.

Montiel, P. and C. Reinhart (1999): "Do Capital Controls and Macroeconomic Policies Influence the Volume and Composition of Capital Flows? Evidence from the 1990s," Journal of International Money and Finance, 18 (4): 619-635.

Prasad, E. S., K. Rogoff, Wei, S. J. and A. Kose (2003): “Effects on Financial Globalization on Developing Countries: Some Empirical Evidence”, IMF Occasional Paper No. 220, September.

Rogoff, K. (1999): “International Institutions for Reducing Global Financial Instability,” The Journal of Economic Perspectives, 13(4): 21-42.

Rubin, R. E. (2003): In an Uncertain World: Tough Choices from Wall Street to Washington. New York: Random House.

Simona, F. N. and F. Sorsa (1999). "A Review of Capital Account Restrictions in Chile in the 1990s," IMF Working Paper 99/32.

Soto, C. (1997): “Controles a los Movimientos de Capitales: Evaluación Empírica del Caso Chileno”. Mimeo. Banco Central de Chile.

Stiglitz, J. (1999): “Bleak Growth Prospects for the Developing World,” International Herald Tribune, April 10-11. 
(2000): “Capital Market Liberalization, Economic Growth, and Instability,” World Development, 28 (6): 1075-1086.

(2002): Globalization and its Discontents. W.W. Norton, New York and London.

Valdés-Prieto, S. and M. Soto. 1998. "The Effectiveness of Capital Controls: Theory and Evidence from Chile." Empirica, 25(2): 133-164. 
Table 1: Garch specification. Mean equation

\begin{tabular}{ccccccc} 
& \multicolumn{2}{c}{ No lags } & \multicolumn{2}{c}{ One Lag } & \multicolumn{2}{c}{ Two Lags } \\
& $\underline{\text { Point }}$ & $\underline{\underline{\text { StDev }}}$ & $\underline{\underline{\text { Point }}}$ & $\underline{\underline{\text { StDev }}}$ & $\underline{\underline{\text { Point }}}$ & $\underline{\underline{\text { StDev }}}$ \\
$c_{0}$ & -0.6471 & 0.041 & -0.5269 & $\cdot$ & -0.5209 & 0.0111 \\
$x_{t}$ & 0.1557 & 0.026 & 0.1356 & $\cdot$ & 0.1340 & 0.0376 \\
$\tau_{t}$ & 0.1211 & 0.042 & 0.0997 & 0.0441 & 0.1009 & 0.0584 \\
$x_{t} \tau_{t}$ & -0.1343 & 0.013 & -0.1145 & 0.0198 & -0.1111 & 0.0262 \\
$f_{t-1}$ & & & 0.2583 & $\cdot$ & 0.2707 & 0.0517 \\
$x_{t-1}$ & & & 0.0139 & $\cdot$ & 0.0117 & 0.0618 \\
$\tau_{t-1}$ & & & -0.0220 & 0.0441 & -0.0209 & 0.0804 \\
$x_{t-1} \tau_{t-1}$ & & & 0.0098 & 0.0198 & 0.0100 & 0.0374 \\
$f_{t-2}$ & & & & & 0.0168 & 0.0512 \\
$x_{t-2}$ & & & & & 0.0084 & 0.0553 \\
$\tau_{t-2}$ & & & & & -0.0022 & 0.0573 \\
$x_{t-2} \tau_{t-2}$ & & & & & -0.0029 & 0.0273
\end{tabular}


Table 2: Estimates from Garch specification. Variance equation.

\begin{tabular}{ccccccc} 
& \multicolumn{2}{c}{ No lags } & \multicolumn{2}{c}{ One Lag } & \multicolumn{2}{c}{ Two Lags } \\
& $\underline{\text { Point }}$ & $\underline{\underline{\text { StDev }}}$ & $\underline{\text { Point }}$ & $\underline{\text { StDev }}$ & $\underline{\text { Point }}$ & $\underline{\text { StDev }}$ \\
$\eta_{0}$ & 0.0053 & 0.0005 & 0.0013 & $\cdot$ & 0.0006 & $\cdot$ \\
garc0 & 0.2504 & 0.0512 & 0.2282 & 0.0665 & 0.2306 & 0.1647 \\
arch0 & 0.4667 & 0.0451 & 0.4729 & 0.0404 & 0.4762 & 0.0594 \\
$x_{t}$ & 0.0008 & 0.0001 & 0.0020 & 0.0007 & 0.0019 & 0.0007 \\
$\tau_{t}$ & 0.0022 & 0.0001 & 0.0018 & 0.0149 & 0.0018 & 0.0181 \\
$x_{t} \tau_{t}$ & -0.0007 & & -0.0008 & 0.0002 & -0.0011 & 0.0021 \\
garc1 & & & 0.0034 & 0.0456 & 0.0065 & 0.1126 \\
arch1 & & & 0.0031 & 0.0297 & 0.0050 & 0.1780 \\
$x_{t-1}$ & & & -0.0014 & 0.0007 & -0.0014 & 0.0012 \\
$\tau_{t-1}$ & & & 0.0009 & 0.0149 & -0.0003 & 0.0218 \\
$x_{t-1} \tau_{t-1}$ & & & 0.0000 & 0.0002 & 0.0001 & 0.0023 \\
garc2 & & & & & 0.0037 & 0.0778 \\
arch2 & & & & & 0.0014 & 0.0489 \\
$x_{t-2}$ & & & & & 0.0002 & 0.0008 \\
$\tau_{t-2}$ & & & & & 0.0005 & 0.0043 \\
$x_{t-2} \tau_{t-2}$ & & & & & 0.0004 & 0.0007
\end{tabular}




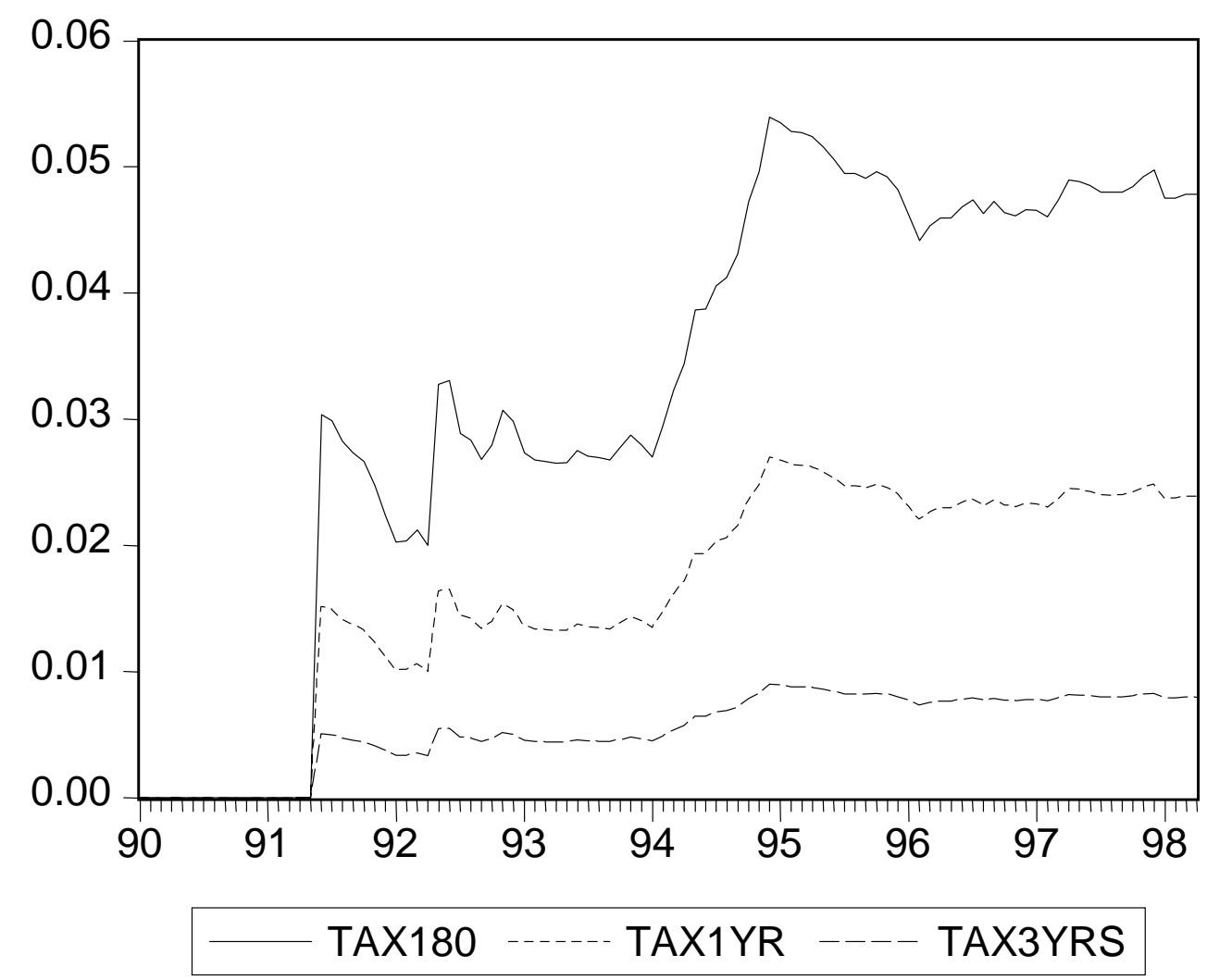

Figure 1: Tax Equivalent of Capital Controls: Stay of 180 days, 1 year and 3 years 


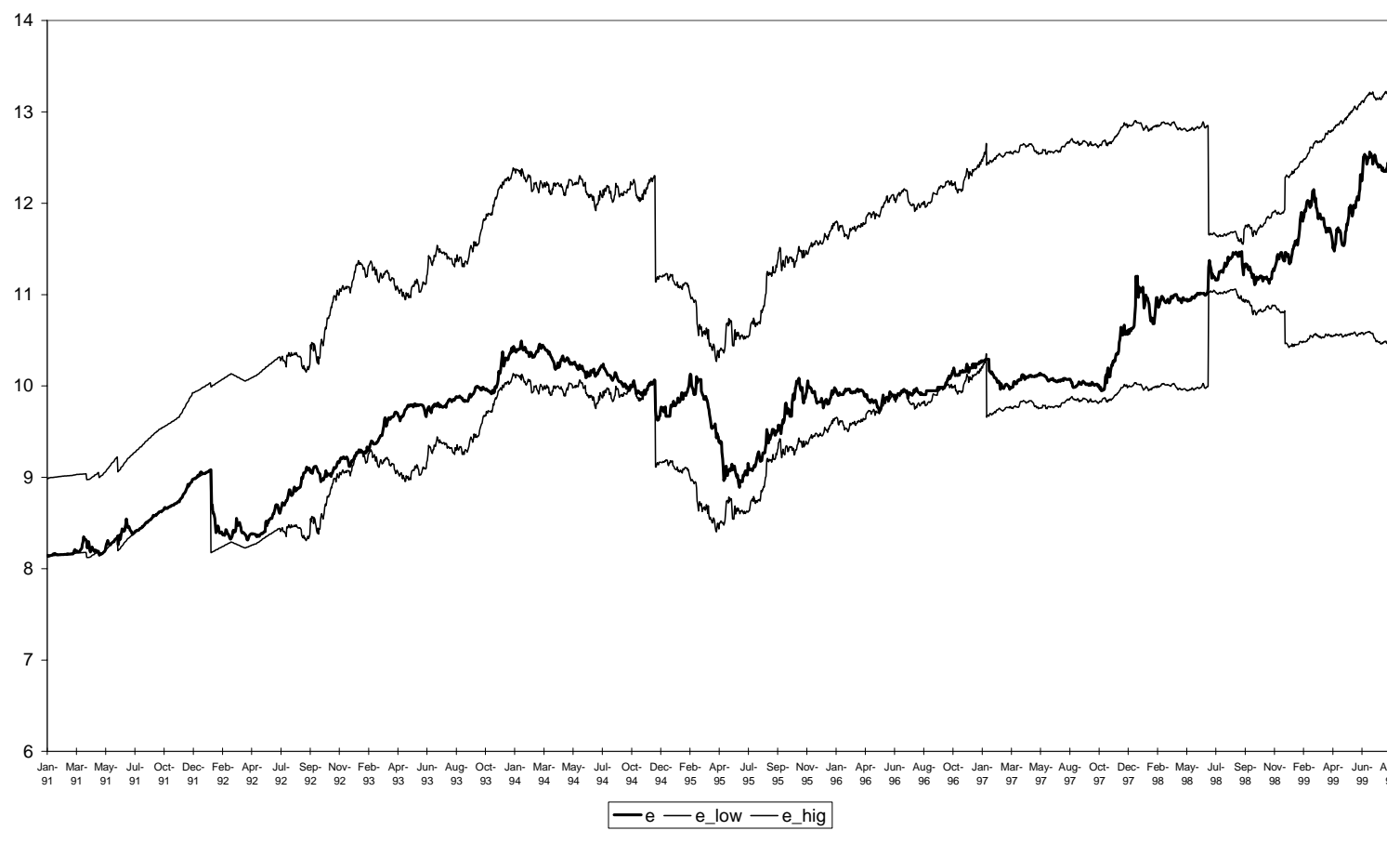

Figure 2: exchange rate and exchange rate bands. 


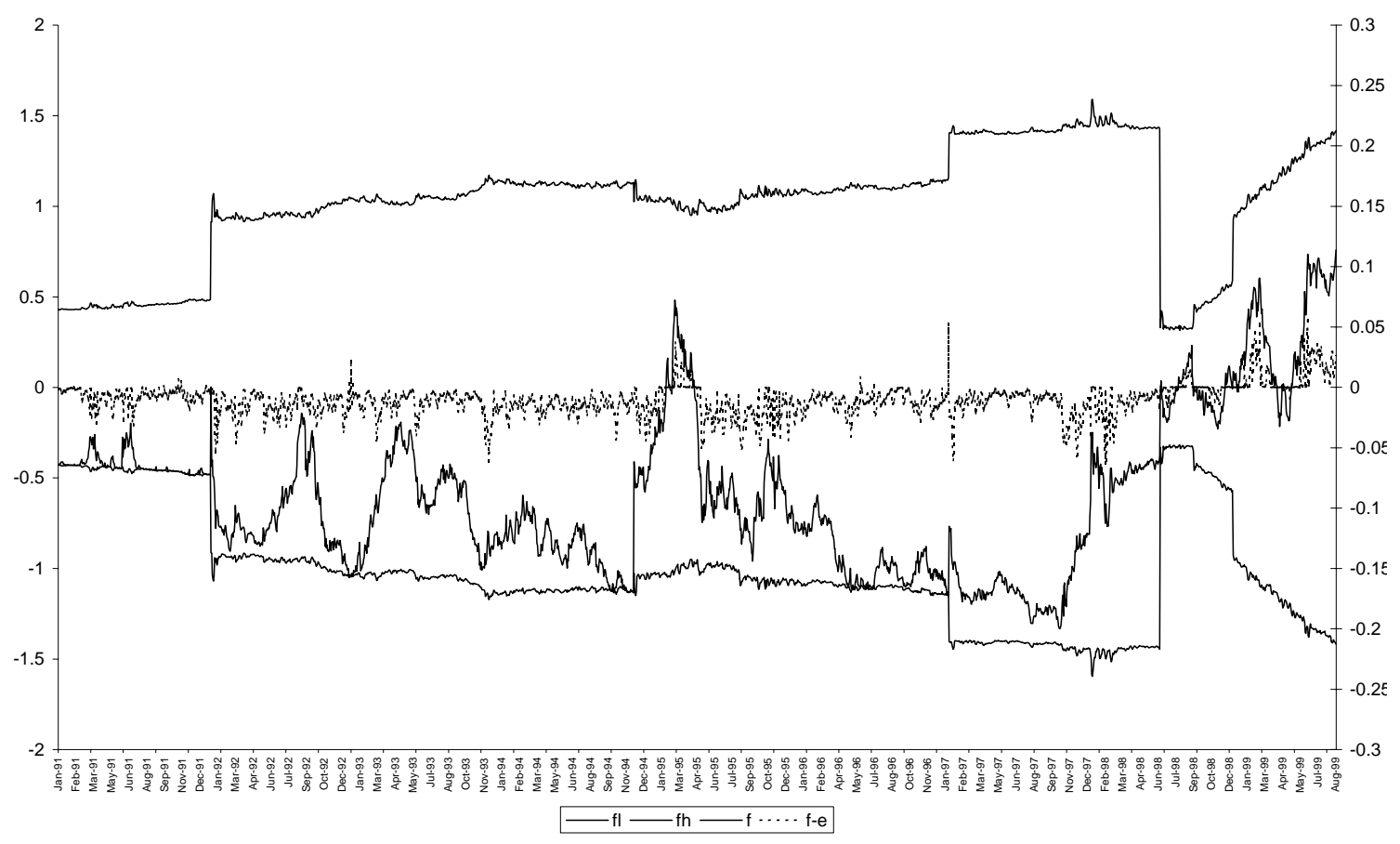

Figure 3: Exchange Rate, Bands, and the difference between the nominal exchange rate and the shadow exchange rate. 


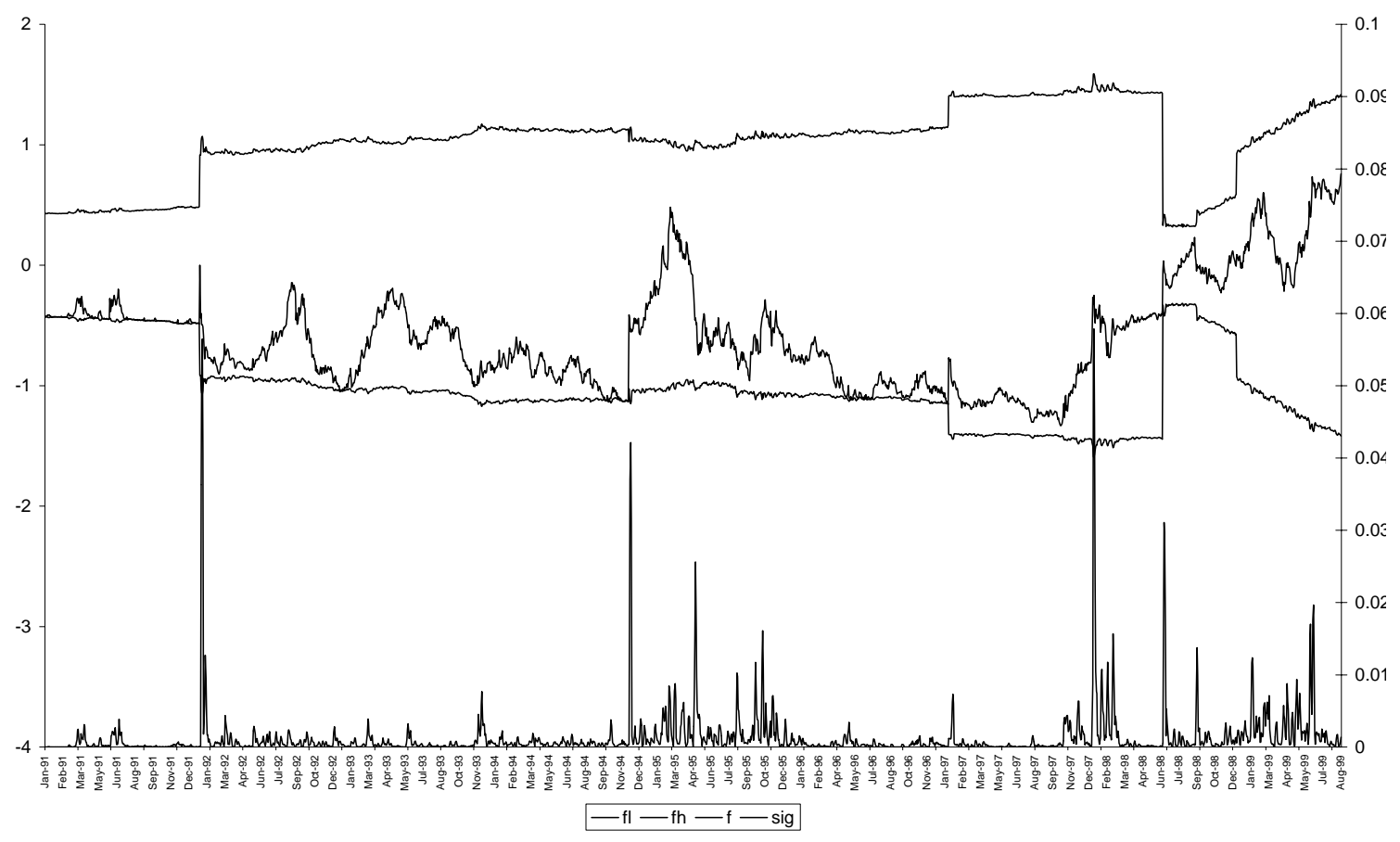

Figure 4: Exchange rate, Bands, and rolling window variance (5 days) of the shadow exchange rate 


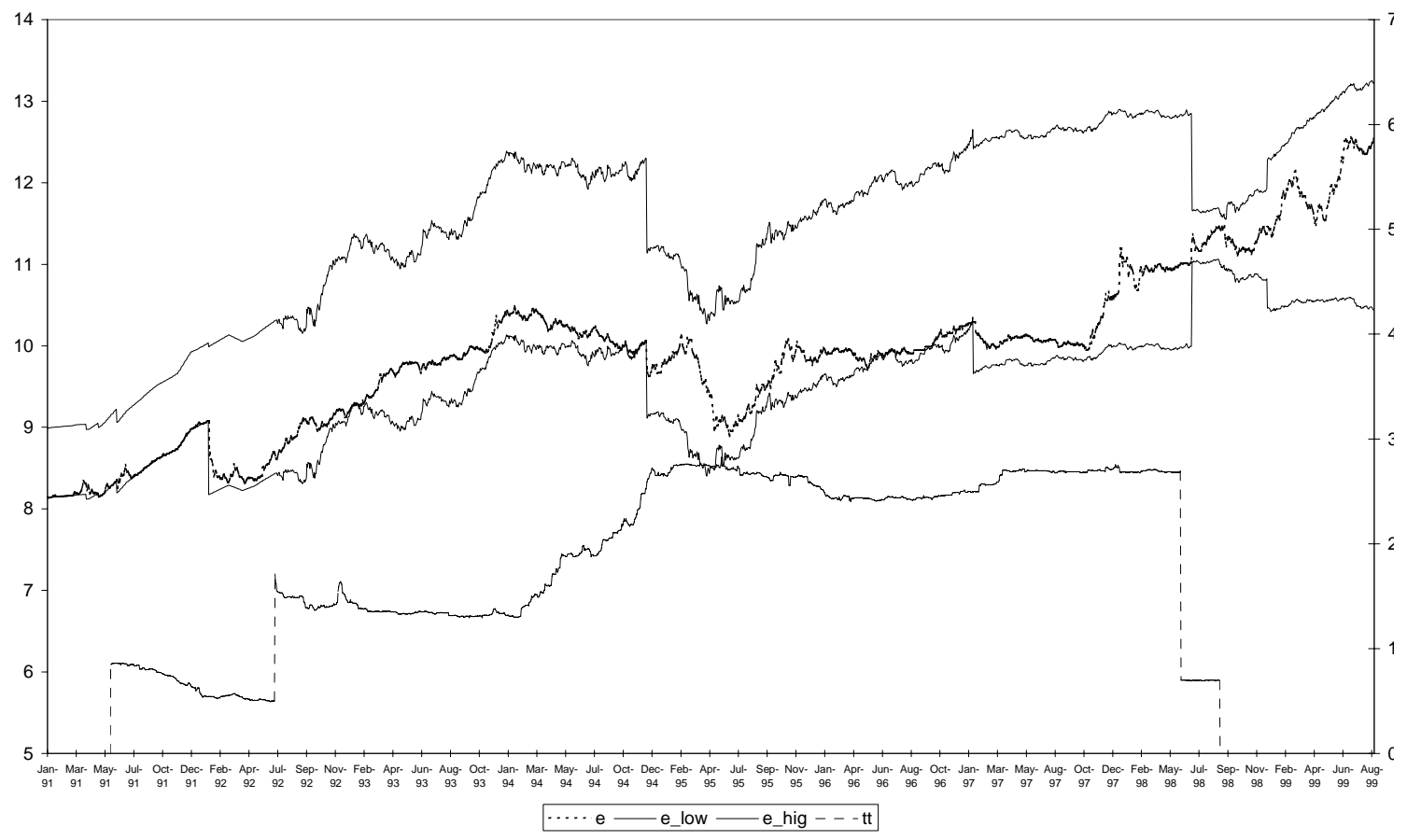

Figure 5: Exchange rate, Bands, and the equivalent tax rate implied by the capital controls. 


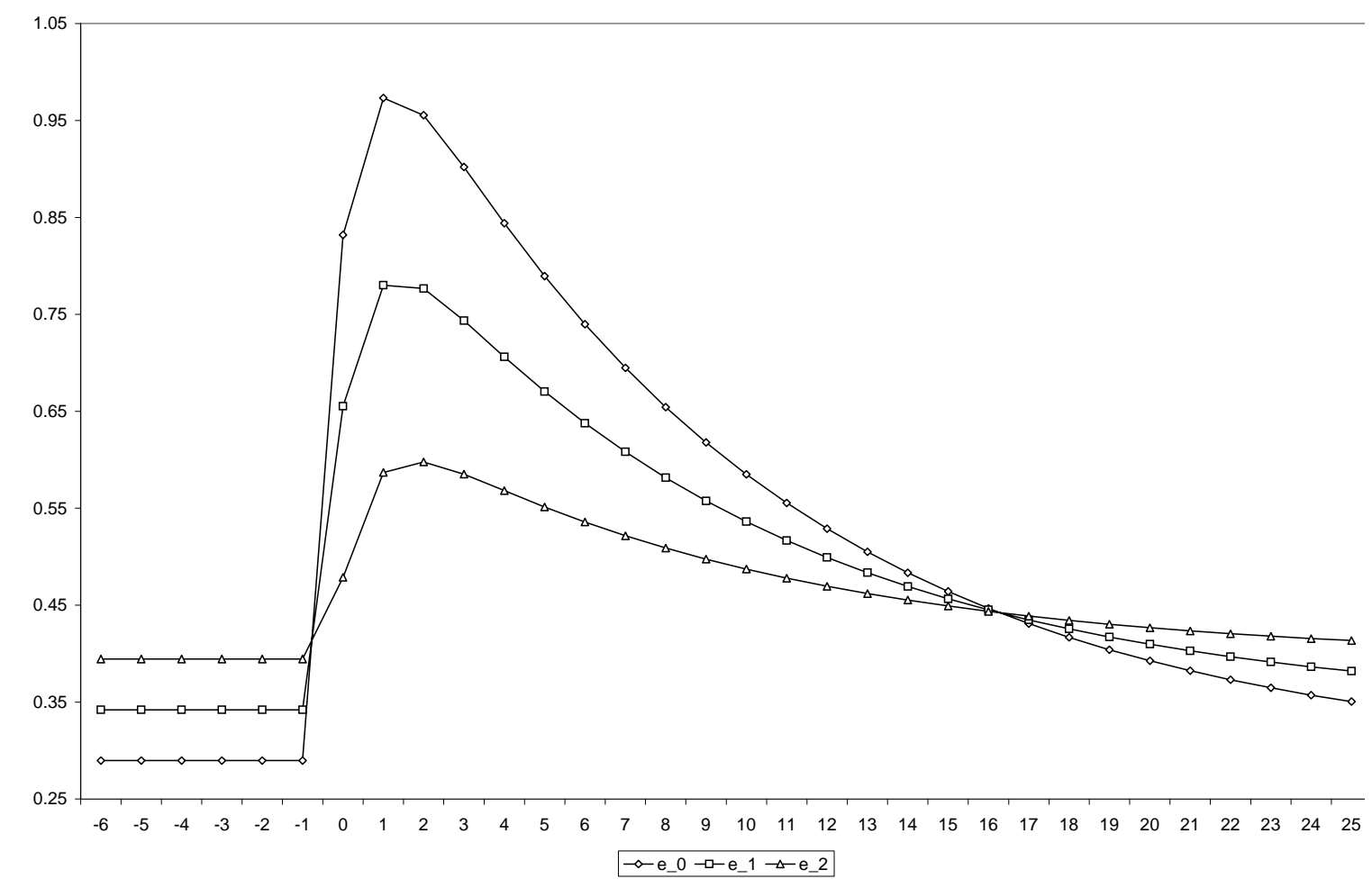

Figure 6: Impulse response on the nominal exchange rate of a persistence (0.8) external increase in the interest rate, for different degrees of capital control ( $0,0.5$ and 1 standard deviations). 


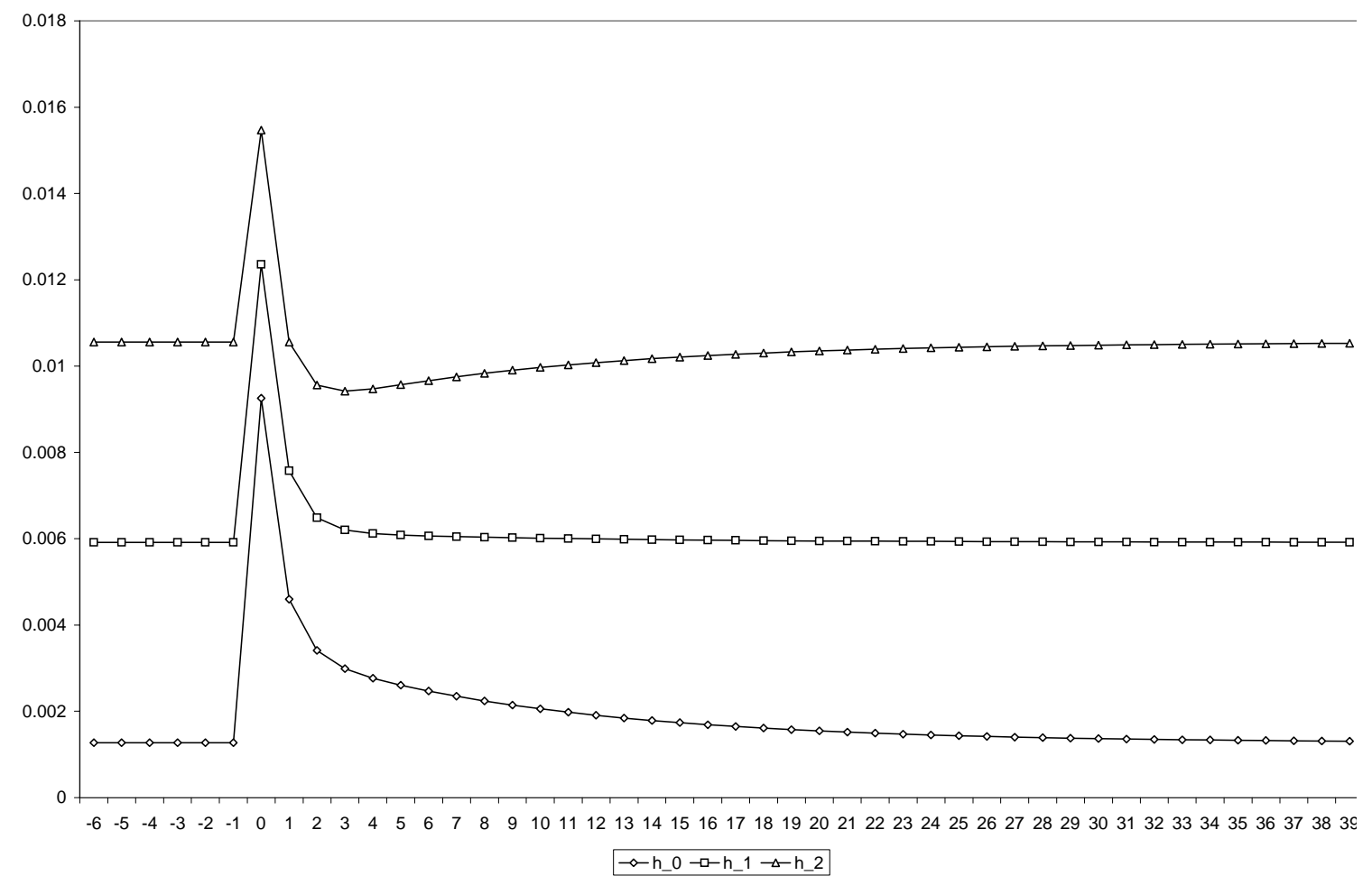

Figure 7: Conditional variance predicted by the GARCH. Impulse response to a shock to the external interest rate for several degrees of capital controls. 


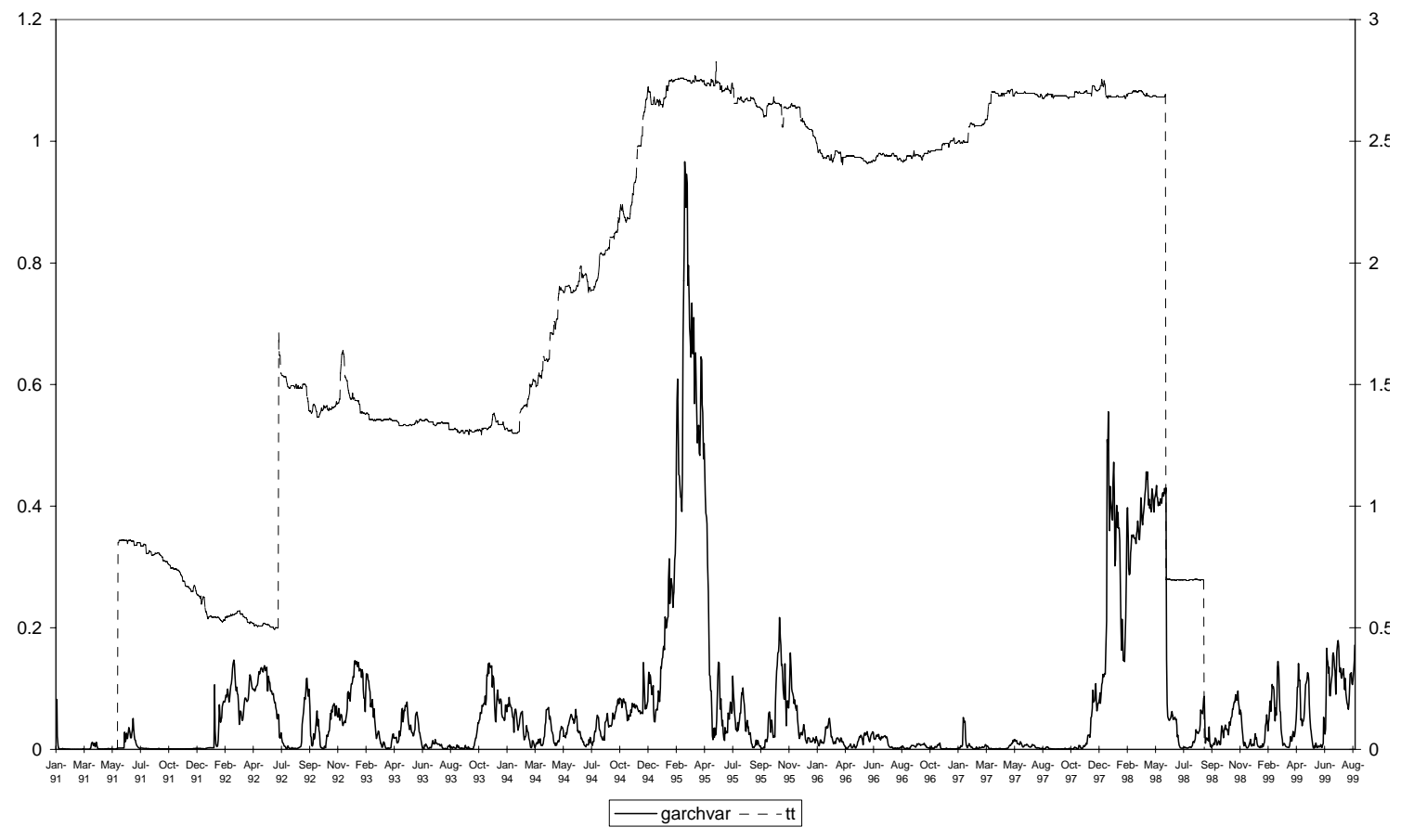

Figure 8: Conditional volatility and tax rate implied by the capital control. 